\title{
Mesoscale heat waves induced by orography
}

\author{
I. Gladich ${ }^{1}$, I. Gallai ${ }^{2}$, D. B. Giaiotti ${ }^{2}$, Gp. Mordacchini ${ }^{3}$, A. Palazzo ${ }^{3}$, and F. Stel ${ }^{2}$ \\ ${ }^{2}$ ARPA CRMA - Regional Center for Environmental Modelling, via Cairoli 14, 33057 Palmanova, Italy \\ ${ }^{1}$ ICTP - the "Abdus Salam" International Centre for Theoretical Physics, Miramare, Trieste, Italy \\ ${ }^{3}$ CNMCA - Centro Nazionale di Meteorologia e Climatologia Aeronautica, Pratica di Mare, 00040 Rome, Italy
}

Received: 28 December 2007 - Revised: 11 June 2008 - Accepted: 5 July 2008 - Published: 18 July 2008

\begin{abstract}
This work is devoted to the analysis of an unusual and sudden thermal fluctuation that interested portions of Friuli Venezia Giulia (Italy) during the night of 27 July 1983. The whole 1983 summer was extremely warm in Europe and in particular on the Italian peninsula, from the Alps down to Sicily. Nevertheless, the day of 27 July 1983 in Friuli Venezia Giulia deserves special attention because the observed maximum temperatures did not occur during day-time but during night-time (from 23:00 up to 24:00 LT, 21:00-22:00 UTC). Peaks of $34.8^{\circ} \mathrm{C}$ and values of relative humidity of the order of $28 \%$ were registered by the official network of weather stations. This event interested mainly the central-eastern part of the plain of Friuli Venezia Giulia, a few kilometers far from the Slovenian border and relieves. The thermal anomalies lasted up to an hour, then temperatures decreased toward values more usual for the climate of the month. The study of this event is carried out with the aid of the AR-WRF numerical atmospheric model, initialized through the ECMWF analysis. The numerical simulations highlight the important role played by orography, jointly with the peculiar thermal structure of the atmosphere, for the enhancing of the internal wave pattern over that area. According to the sensitivity studies realized, the amplification of the internal wave pattern might represent a possible explanation for that meteorological enigma.
\end{abstract}

\section{The different classes of thermal anomalies}

Even if there is not a universally accepted definition of "heat wave" (Robinson, 2001; Meehl and Tebaldi, 2004) the long lasting thermal anomalies are usually taken into account when they represent "a period of abnormally and uncomfortably hot and usually humid weather" (Huschke, 1989) or more quantitatively, following the recommendations of WMO, they are considered as relevant when they last for a period of more than five consecutive days with a daily maximum temperature which exceeds by $5^{\circ} \mathrm{C}$ the maximum temperature normal value, obtained for the same area in the period (1961-1990). Following the same tradition, most intense heat waves are usually called "heat storms" when the daily maximum temperature reaches $38^{\circ} \mathrm{C}$ for three or more consecutive days (Frich et al., 2002). Apart from the above mentioned "long lasting" thermal anomalies, there are other thermal anomalies observed at the ground which last for shorter amounts of time (hours or minutes) and over smaller areas (hundreds of squared $\mathrm{km}$ ). Typically these ther- mal anomalies are related to Foehn episodes (Seibert, 1990; Yoshino, 1976; Giaiotti et al., 2007) but not all the observed sudden local temperature increases can be explained through the Foehn mechanism. In fact, mainly in the last few decades, thanks to the development of weather mesonetworks, the existence of "heat bursts" has been confirmed (see, among others, Froude and Simmonds, 1965; Johnson, 1983). Currently the amount of reports on "heat waves" is grown enough to permit the development of a preliminary climatology of these events at least in some areas (Lane, 2002). But the class of possible mechanisms responsible for abnormal atmospheric heatings, however, is not exhausted by these cases, in fact there is at least one other episode in which the above mentioned mechanisms could not be taken into account to explain the observations. This is the case of the 27 July 1983 episode which took place at evening-time on the Friuli Venezia Giulia plain. 


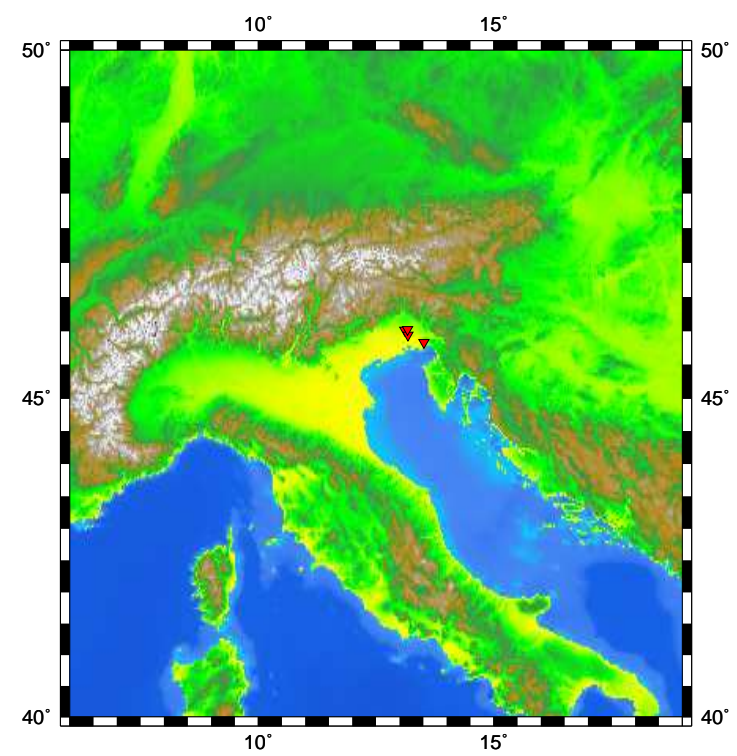

(a) Italian peninsula

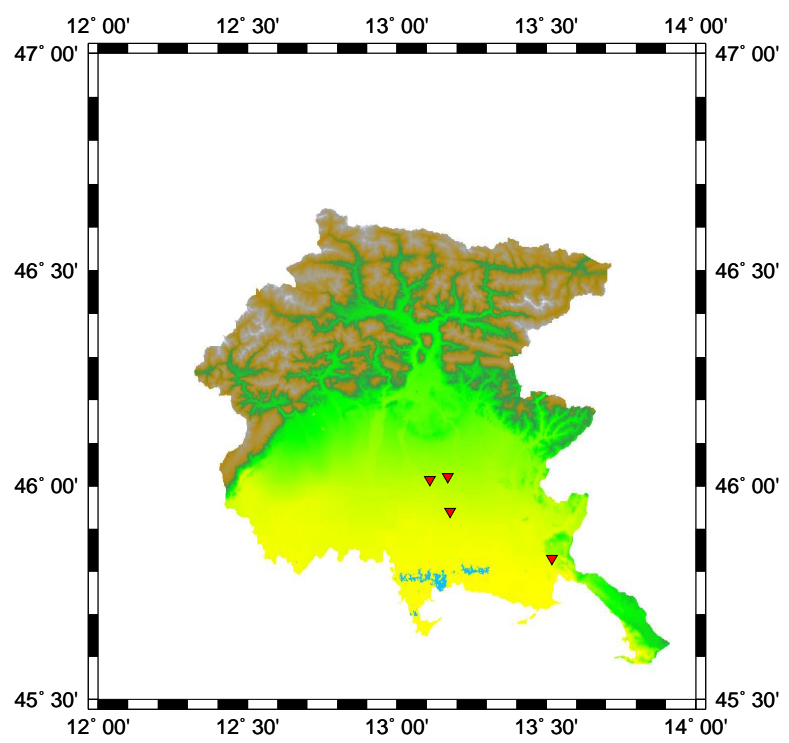

(b) Friuli Venezia Giulia region

Figure 1. Geography and orography of Friuli Venezia Giulia. The triangles indicate the places where a nearly contemporary abnormal heating was observed and reported during the evening of 27 July 1983.

\section{The 27 July 1983 abnormal heating}

During the evening of 27 July 1983 some areas of the Friuli Venezia Giulia plain (see Fig. 1) experienced an abnormal heating nearly at 23:00 local time (21:00 UTC). This abnormal heating, according to the witnesses, was quite sudden and it lasted for nearly half an hour, then temperatures returned back to the previous normal values for the period of the year and time-of-the-day. At the same time, relative humidity decreased toward very low values and rose again toward normal values as soon as temperature decreased. According to recorded values, during the event temperature increased up to $34.8^{\circ} \mathrm{C}$ and relative humidity decreased up to $28 \%$ and, after half an hour, temperature returned back to $24.0^{\circ} \mathrm{C}$ and relative humidity to $80 \%$. This specular behaviour of temperature and relative humidity points the attention toward adiabatic mechanisms but no significant winds were recorded, nor during the event, neither during the whole day. In particular there were no winds blowing from north and/or north-east as had to be the case if the event were due to foehn. In fact, north and north-east winds are katabatic flows for the peculiar orography of that region (see Fig. 1) and often produce, specially in summer, adiabatic heatings. No precipitations were recorded neither reported by the witnesses, then the "heat burst" hypothesis might be rejected even because no gusty winds were observed during the event, as already written. Under the synoptic point of view, the evening of 27 July was characterized by a persistent warm ridge extending from Algeria up to northern Europe. This pressure ridge favours, aloft, a weak anticyclonic flow from
NW over Friuli (see Fig. 2). In particular, at $850 \mathrm{hPa}$, a warm tongue (e.g., the $25^{\circ} \mathrm{C}$ isotherm) reaches northern Italy and slowly moves from west toward east. Over Friuli, at the $850 \mathrm{hPa}$ isobaric level, the maximum temperature is reached during the evening of the event (see Fig. 2). Thanks to the data obtained through a radiosounding carried out by Italian Air Force almost in the middle of the Friulian plain (Campoformido, WMO code 16044), a closer look at the atmospheric vertical structure over the area of the event is possible and it reveals a weak static stability (see Fig. 3). In particular, a Brunt-Vaisala frequency of the order of $5 \times 10^{-3} \mathrm{~s}^{-1}$ is observed at 00:00 UTC of $28 \mathrm{July}$, which is comparable with the value $1 \times 10^{-2} \mathrm{~s}^{-1}$ obtained with the WRF numerical simulations. The climatic values on the same area are of the order of $2 \times 10^{-1} \mathrm{~s}^{-1}$ (Gladich, 2005) comparable with those obtained for mid latitudes (Gossard and Hook, 1975). Moreover, the equivalent potential temperature computed using the ground values of pressure and temperature recorded during the event gives the same value observed at $850 \mathrm{hPa}$.

\section{Numerical simulations of the event}

The AR-WRF numerical system (http://www.wrf-model. org) is used adopting, as initial and boundary conditions, the ECMWF analysis of 27 July 1983 at 00:00 UTC. The runs are carried out with the model version 2.1.1 using three nests $(50 \mathrm{~km}, 10 \mathrm{~km}$ and $3.3 \mathrm{~km}$ in horizontal resolution) and 31 vertical levels with a top pressure of $50 \mathrm{hPa}$. The boundary layer scheme was that of the Yonsei University (Hong et al., 2006), surface layer was parametrized through 


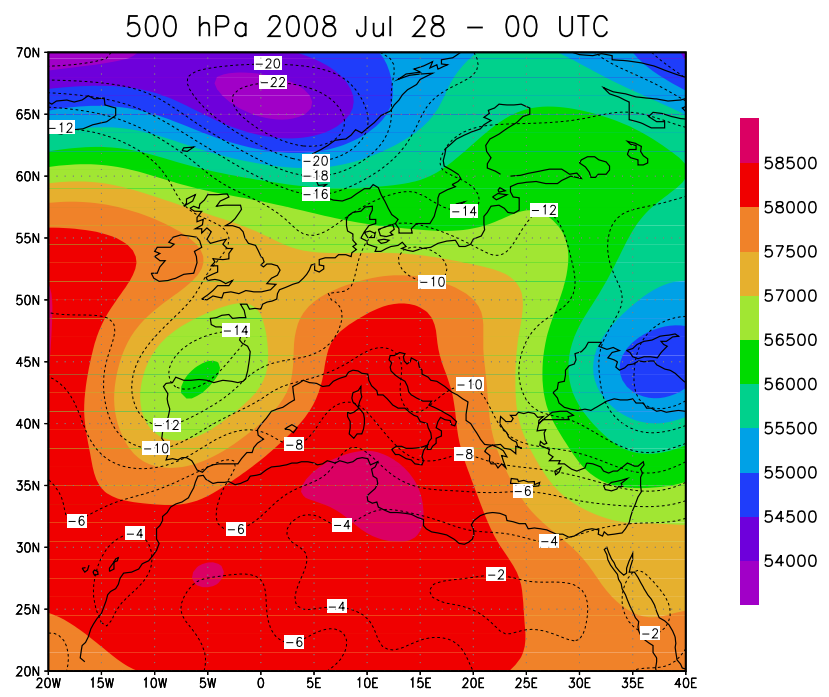

(a) $500 \mathrm{hPa}$ geopotential and temperature

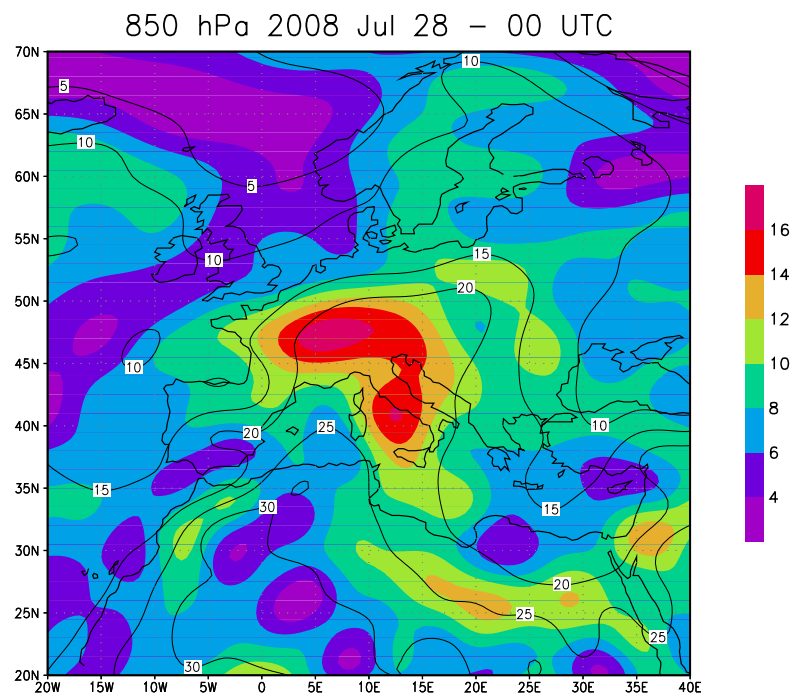

(b) $850 \mathrm{hPa}$ temperature and specific humidity

Figure 2. Synoptic structure of the atmosphere over Europe at 00:00 UTC of 28 July 1983. Panel (a) reports shaded the $500 \mathrm{hPa}$ geopotential height $(\mathrm{m})$ while temperature is in dashed lines; panel (b) reports shaded the specific humidity $(\mathrm{g} / \mathrm{kg})$ at $850 \mathrm{hPa}$ while temperature $\left({ }^{\circ} \mathrm{C}\right)$ is in solid lines

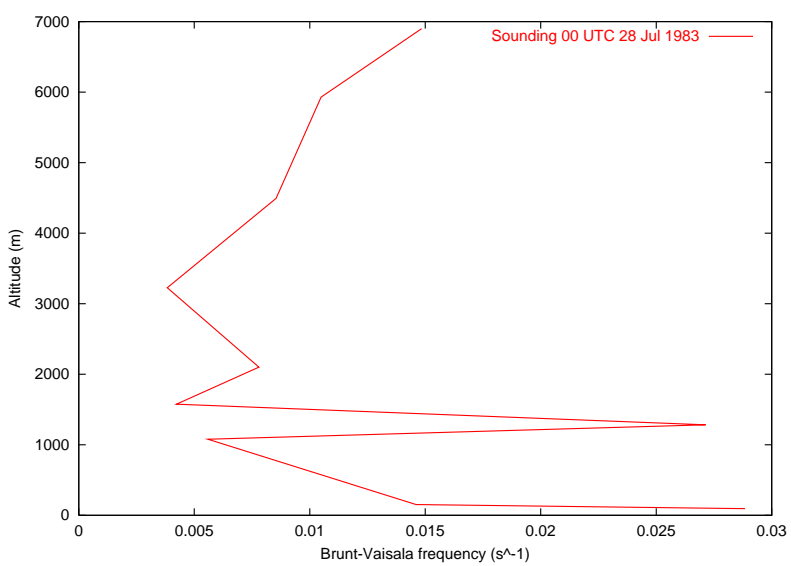

(a) Brunt-Vaisala frequency

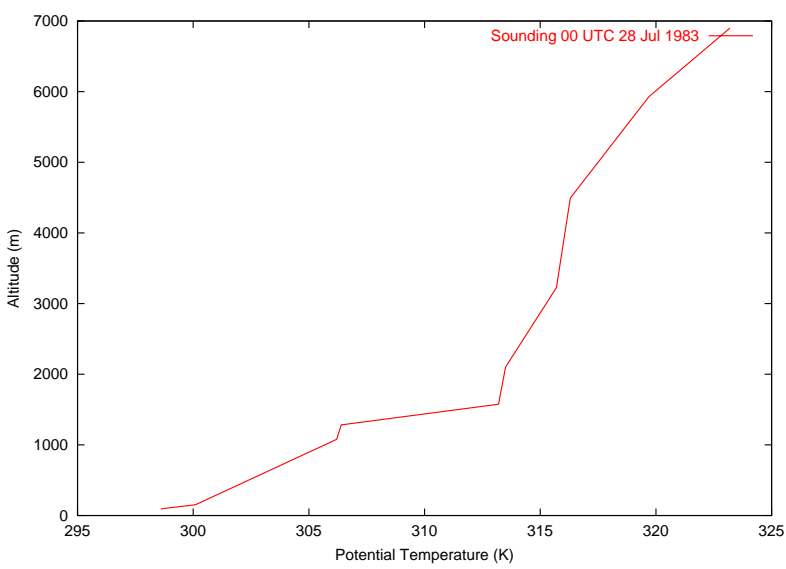

(b) Potential Temperature

Figure 3. Vertical thermal structure of the atmosphere over Friuli Venezia Giulia revealed by the 00:00 UTC of 28 July 1983 atmospheric sounding carried out by Italian Air Force at Campoformido (WMO code 16044). Panel (a) reports the Brunt-Vaisala frequency; panel (b) reports potential temperature

the Monin-Obukhov scheme, while radiative processes were parametrized through the "rapid radiative transfer model" (long waves, Mlawer et al., 1997) and Dudhia scheme (short waves, Dudhia, 1989).

The results obtained through this numerical system (see Fig. 4) show clearly a warm spot at $925 \mathrm{hPa}$ (panel a) not produced by horizontal advection, but by a vertical descent of the air (panel b).
According to the numerical simulations, the sudden increase of temperature near to the ground is the result of the adiabatic compression of a vertical atmospheric wave, even if, in the simulation, the wave is not enough ample to reproduce exactly the temperature anomaly. The wave pattern is consistent with the atmospheric stable stratification and the large wave amplitude is consistent with the relatively low Brunt-Vaisala frequency which, assuming a group velocity of the order of $10 \mathrm{~m} / \mathrm{s}$, corresponds to a wave length of the 
$\mathrm{T}(\mathrm{C})$ at $925 \mathrm{hPa}$

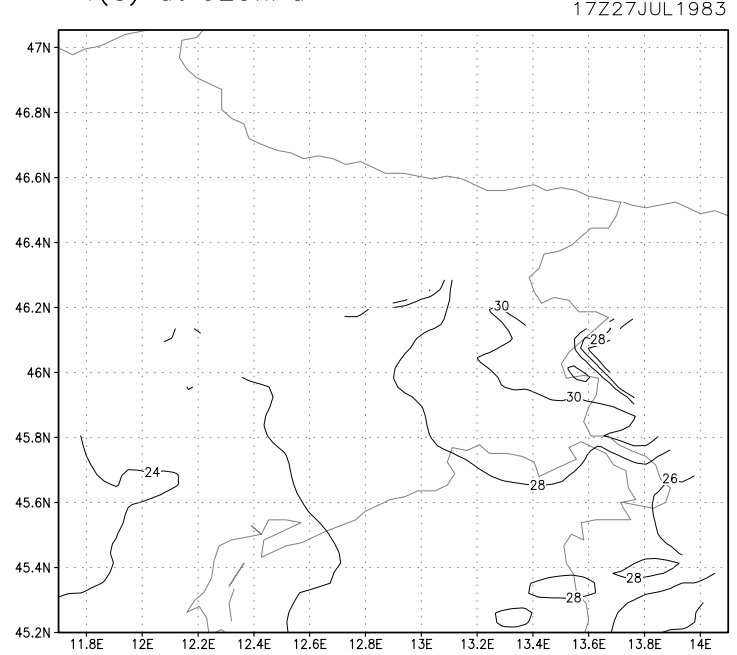

(a) Temperature field at $925 \mathrm{hPa}$

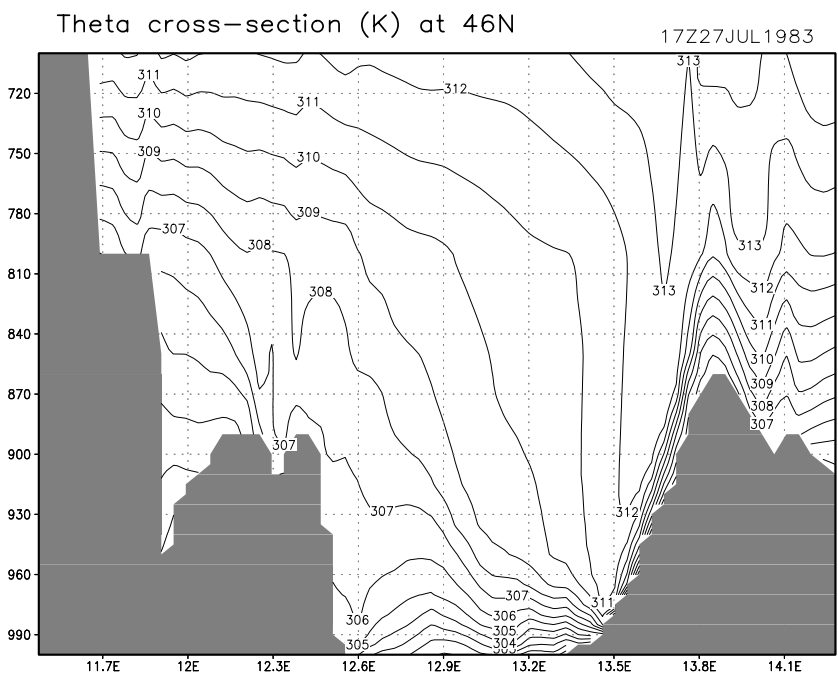

(b) Potential temperature cross-section

Figure 4. Thermal structure at the $925 \mathrm{hPa}$ (a) and potential temperature vertical cross section (b) realized along the parallel $46 \mathrm{~N}$.

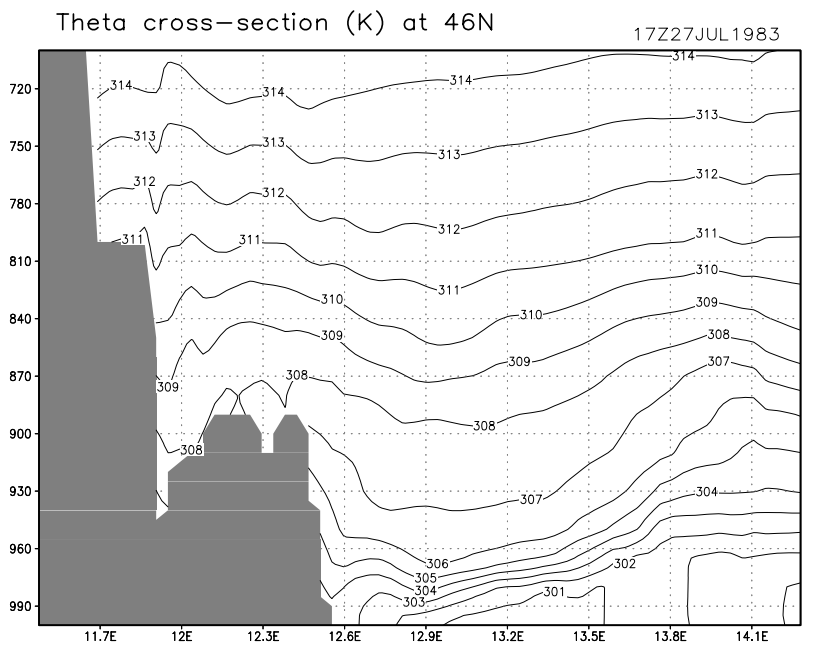

(a) Flattened eastern relieves

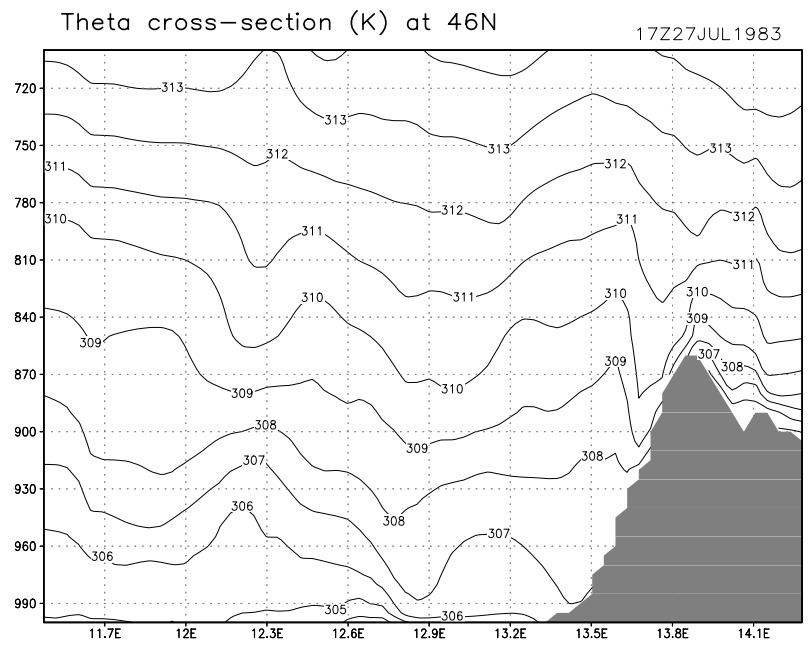

(b) Flattened western relieves

Figure 5. Potential temperature vertical cross section realized along the $46 \mathrm{~N}$ obtained flattening the eastern relievels (a) and the western relieves (b).

order of $16 \mathrm{~km}$, which is roughly $1 / 2$ the order of magnitude of the Friulian plain amplitude along the NW direction, i.e., along the direction of the wind field aloft and is roughly 8 times the order of magnitude of the relieves height. To analyse the role of orography in the wave pattern, three different class of simulations are carried out. In detail the orography is modified: i) flattening the eastern ridge (see Fig. 5a); ii) flattening the western ridge (see Fig. 5b); iii) narrowing the amplitude of the Friulian plain (not shown). The result of that class of simulations shows that the interplay between flows and orography is anyway important, and only a precise distri- bution of the relieves can reproduce the timing and amplitude of the wave pattern, nevertheless the major role is played by the eastern orographic ridge, without which the wave pattern does not form at all (see Fig. 5a). According to the above simulations, the enhancement of the waves amplitude should be interpreted as a result of the energy conservation mechanism when the available volume for the wave propagation is reduced because of orography. 


\section{Conclusions}

Numerical simulations carried out through the AR-WRF system, initialized through the ECMWF analysis, show that the sudden and short-lasting evening heating of 27 July 1983 should be due to an adiabatic descent of warm air originally positioned around the $850 \mathrm{hPa}$ level. This descent, in its turn, is the result of the interplay between a NW warm flow and orography in a weakly stratified environment. Sensitivity runs performed through the WRF numerical model enhancing orography (amplifying peaks and deepening valleys), flattening orography (western and eastern part of the Friulian Alps relieves independently) and deforming geography (reducing the amplitude of the Friulian plain) show that the amplification of the wave pattern, fundamental for the maximum wideness of the vertical displacement, is extremely sensitive to the orography shape and height. Even slight changes in shape and height will reduce the extension of the air-mass vertical displacement, then the amount of the sensible heating near to the ground. This high sensitivity to the boundary conditions is considered as an explanation of the exceptionality of that event. The best results obtained during the sensitivity runs are those shown in Fig. 4, which do not reproduce exactly what observed at the ground. In particular the simulations reproduce a thermal increase in the right location but weaker $\left(32^{\circ} \mathrm{C}\right.$ in place of $\left.34.8^{\circ} \mathrm{C}\right)$ and occurring a few hours before than that observed.

Acknowledgements. Part of this work has been carried out in the frame of the FORALPS project (www.foralps.net) financed by the ERDF INTERREG IIIB "Alpine Space" Programme. The authors would like to thank even the ECMWF for the supplying of the initial and boundary conditions for the numerical simulations.

Edited by: F. Stel and D. B. Giaiotti

Reviewed by: two anonymous referees

\section{References}

Bernstein, B. C. and Johnson, R. H.: A dual-doppler radar 510 B study of an OK PRE-STORM heat burst event, Mon. Weather Rev., 122, 259-273, 1994.

Dudhia, J.: Numerical study of convection observed during the winter monsoon experiment using a mesoscale two-dimensional model, J. Atmos. Sci., 46, 3077-3107, 1989.

Frich, A., Alexander, L. V., Della-Marta, P., Gleason, B., Haylock, M., Klein Tank, A. M. G., and Peterson, T.: Observed coherent changes in climatic extremes during the second half of the twentieth century, Climate Res., 19, 193-212, 2002.

Froude, G. and Simmonds, J.: Phenomenal temperature oscillations in Aden, Meteor. Mag., 94, 185-187, 1965.

Giaiotti, D. B., Steinacker, R., and Stel, F.: Atmospheric Convection: Research and Operational Forecasting Aspects, Springer, Wien, NewYork, Udine, 2007.

Gladich, I.: Study of non hydrostatic effects in the interaction between flow and orography, Thesis dissertation, University of Trieste, 2005 (in Italian).

Gossard, E. E. and Hooke, W. H.: Waves in the Atmosphere, Elsevier Scientifc Publishing Company, 1975.

Hong, S.-Y., Noh, Y., and Dudhia, J.: A new vertical diffusion package with an explicit treatment of entrainment processes, Mon. Weather Rev., 134, 2318-2341, 2006.

Huschke R. E.: Glossary of meteorology, American Meteorological Society, Boston, 1989.

Johnson B. C.: The heat burst of 29 May 1976, Mon. Weather Rev., 111, 1776-1792, 1983.

Lane J. D.: Climatological analysis of heatbursts in Oklahoma, Proceedings of the 21st AMS Conference on Severe Local Storms, abstract no. P2.9, 2002.

Meehl, G. A. and Tebaldi, C.: More Intense, More Frequent, and Longer Lasting Heat Waves in the 21st Century, Science, 305, 994-997, 2004.

Mlawer, E. J., Taubman, S. J., Brown, P. D., Iacono, M. J., and Clough, S. A.: Radiative transfer for inhomogeneous atmospheres: RRTM, a validated correlated-k model for the longwave, J. Geophys. Res., 102D, 16 663-16682, 1997.

Robinson, P. J.: On the Definition of Heat Waves, J. App. Meteorol., 40, 762-775, 2001.

Seibert P.: South Foehn Studies Since the ALPEX Experiment, Meteorol. Atmos. Phys., 43, 91-103, 1990.

Yoshino, M. M.: Local wind Bora, University of Tokio Press, Tokio, 1976. 